\title{
СИНТЕЗ НИТРОЗОРЕЗОРЦИНОВ И ИХ КОМПЛЕКСО- ОБРАЗОВАНИЕ С КОБАЛЬТОМ
}

\author{
(Представил О. Киррет)
}

В аналитической химии для обнаружения и количественного определения кобальта широко применяются (напр., [1]) реагенты, содержащие в молекуле фрагмент с нитрозо- и фенольной гидроксильной группами, находящимися относительно друг друга в орто-положении:<smiles>C/C=C(\C)[N+](=O)/C=C(/C)C(=O)O</smiles>

В ассортимент органических реактивов на кобальт для весового и фотометрического определения включен 1-нитрозо-2-нафтол, для фотометрического определения - 2-нитрозо-1-нафтол и 1-нитрозо-2-нафтол3,6-дисульфокислота (т.н. нитрозо-R-соль) [ $\left.{ }^{2}\right]$. В гидрометаллургии 1-нитрозо-2-нафтол рекомендуют применять как осадитель для отделения небольших количеств кобальта от никеля [3], а нитрозо-R-соль для экстракции кобальта из остаточных растворов, образующихся при производстве цинка, кадмия или никеля [ [ $]$.

Цель настоящей работы - исследование возможностей синтеза и использования в качестве комплексообразователей для кобальта двух нитрозосоединений резорцинового ряда. Как известно, алкилпроизводные резорцина образуются при термической переработке прибалтийских горючих сланцев и в больших количествах выделяются из смольных вод сланцеперерабатывающих предприятий в виде т. н. сланцевых водорастворимых фенолов. Эти соединения состоят, в основном, из 5 -алкил- $(\sim 40 \%), 2,5$-диалкил- $(\sim 25 \%)$ и 4,5 -диалкилрезорцинов $(\sim 20 \%)$. Основными компонентами являются 5-метил-, 5-этил-, 2,5-диметил- и 4,5-диметилрезорцины [5-7].

\section{Экспериментальная часть}

Синтез нитрозопроизводных 5-метилрезорцина (MRes) и 2,5-диметилрезорцина (DMRes). Нитрозирование ароматических оксисоединений классическим способом осуществляется путем добавления эквимолярного количества амилнитрита к охлажденному щелочному раствору нитрозируемого соединения в абсолютном этиловом спирте [8]. Синтезы 1-нитрозо-2-нафтола [ $\left.{ }^{9}\right]$ и нитрозофенола $\left.{ }^{8}\right]$ можно провести более простым способом - путем подкисления серной кислотой водного раствора, содержащего эквимолярные количества 2-нафтола или фенола, $\mathrm{NaOH}$ и $\mathrm{NaNO}_{2}$. 2-Нитрозо-1-нафтол синтезируют прибавлением водного раствора $\mathrm{NaNO}_{2}$ к спиртовому раствору 1-нафтола, содержащему $\mathrm{ZnCl}_{2}$, с последующей обработкой выпавшей цинковой соли кислотой [?]. 
Согласно $\left[{ }^{10}\right]$, 4-нитрозо-2,5-диметилрезорцин (DMRes-NO) получают классическим способом. Данные о синтезе и свойствах 4-нитрозо-5метилрезорцина (MRes-NO) в литературе отсутствуют.

По нашим опытам, проведенным всеми тремя известными способами, из DMRes образуется идентичный продукт нитрозирования, содержащий $8,35-8,40 \%$ азота (теор. $8,38 \%$ ). Цвет кислотной формы - оранжевый, щелочной соли - темно-бурый, что также согласуется с данными [ $\left.{ }^{10}\right]$. Из MRes мононитрозосоединение можно получить только классическим способом. В водной среде практически полностью происходит динитрозирование. Синтезированная нами и высушенная при $40^{\circ} \mathrm{C}$ (прн более высоких температурах сушки продукт темнеет) кислотная форма MRes-NO была желтого цвета и содержала $8,12 \%$ азота (теор. для MRes-NO $\cdot \mathrm{H}_{2} \mathrm{O}-8,19 \%$ ). Цвет щелочной соли - кирпично-красный.

Определение констант кислотной диссоциации. Реакционноспособной формой оксинитрозосоединений по отношению к катионам является анион, образующийся при кислотной диссоциации оксигруппы, находящейся в орто-положении относительно нитрозогруппы. Область величин $\mathrm{pH}$ существования анионной формы определяется константой кислотной диссоциации $K_{a}$.

В литературе имеются данные о $\mathrm{p} K_{а}$ для нитрозофенола $(6,85), 1$-нитрозо-2-нафтола $(7,63), 2$-нитрозо-1-нафтола $(7,28)$ и нитрозо-R-соли $(7,00)[11,12]$. Соответствующие величины для нитрозорезорцинов отсутствуют. Известно лишь, что при рН среды ниже 2,5 окраска 4-нитрозорезорцина светло-зеленая, а при $\mathrm{pH} \sim 5,6$ - оранжевая [13].

'Для определения $\mathrm{p} K_{a}$ нитрозоалкилрезорцинов применяли потенциометрический метод [14]. В опытах использовали синтезированные нами нитрозосоединения, очищенные двукратной кристаллизацией в этаноле. Концентрация нитрозорезорцинов из-за низкой растворимости их кислотных форм не превышала $2 \cdot 10^{-3}$ моль/дм ${ }^{3}$. Для измерений использовали прибор рН-262 со стеклянным электродом. $K_{a}$ при $20 \pm 2{ }^{\circ} \mathrm{C}$ составляла для MRes-NO 3,31 $\pm 0,02$ и для DMRes-NO 3,46 $\pm 0,03$. Так как эти величины на 3,5-4 единицы ниже известных для нитрозофенола и нитрозонафтолов, провели параллельные измерения спектрофотометрическим методом. При этом оказалось, что регулирование величины $\mathrm{pH}$ предложенными в $\left.{ }^{14}\right]$ буферными растворами неприемлемо вследствие изменения окраски аниона в результате действия органических кислот. Необходимые для измерений величины $\mathrm{pH}$ среды получали путем смешивания разных объемов растворов нитрозосоединения $\left(3,5 \cdot 10^{-4}\right.$ моль/дм $\left.{ }^{3}\right)$, содержащих по $5,0 \cdot 10^{-3}$ моль/дм ${ }^{3} \mathrm{NaOH}$ или $\mathrm{HCl}$. В измерениях использовали спектрофотометр SPEKOL с кюветами 1,00 см, измерения оптической плотности провели при 440 и 450 нм, соответственно, в случае MRes-NO и DMRes-NO. Полученные величины р $K_{a}$ (для MRes-NO $3,33 \pm 0,03$, для DMRes-NO $3,42 \pm 0,06$ ) подтверждают результаты потенциометрического определения.

Таким образом, кислотная диссоциация нитрозорезорцинов действительно начинается в значительно более кислых растворах, чем в случае известных ранее оксинитрозосоединений. Благодаря этому пределы рН комплексообразования с ионами металлов также расширяются в сторону более кислых растворов, где можно ожидать более высокой селективности.

Определение состава комплексов нитрозоалкилрезорцинов с ионами кобальта. Как известно $\left[{ }^{15}\right]$, свободные ионы кобальта из-за высокого нормального окислительного потенциала $\left(E^{0} \mathrm{Co}^{3+} / \mathrm{Co}^{2+}=1,84 \mathrm{~B}\right)$ существуют в водном растворе только в форме Со(II). В комплексных же соединениях $E^{0}$ значительно понижается, благодаря чему происходит полное окисление Со(II) до Со(III) кислородом воздуха, 
По данным $\left[{ }^{13}\right]$, нитрозо-R-соль, нитрозофенол, -крезол и -резорцин образуют с ионами кобальта растворимые комплексы, в которых Со(III) связан с тремя молекулами реагента, а 1-нитрозо-2-нафтол осаждает соединение с формулой $\mathrm{Co}\left(\mathrm{C}_{10} \mathrm{H}_{6} \mathrm{O}_{2} \mathrm{~N}\right)_{3} \cdot 2 \mathrm{H}_{2} \mathrm{O}$. По данным же $\left[{ }^{16}\right]$, в присутствии аммиака и цитрат-ионов образуется $\mathrm{Co}\left(\mathrm{C}_{10} \mathrm{H}_{6} \mathrm{O}_{2} \mathrm{~N}\right)_{2}$. Согласно $\left[{ }^{17}\right]$, в нейтральных и слабощелочных растворах образуется 1-нитрозо-2-нафтолат двухвалентного кобальта $\mathrm{CoR}_{2}$, который в слабокислой среде переходит в $\mathrm{CoR}_{3} \cdot \mathrm{HR}$. В водно-диоксановых растворах, наоборот, нитрозонафтолат двухвалентного кобальта образуется в кислой среде, а в щелочном растворе происходит присоединение третьей молекулы реагента $\left[{ }^{13}\right]$.

Состав комплексов кобальта с MRes-NO и DMRes-NO мы определяли, смешивая разные объемы эквимолярных растворов центрального иона и лиганда [18]. В опытах к 15,0 см$^{3}$ ацетатного (pH 5,3 и 7,6) и аммиачного (pH 8,9) буферных растворов прибавляли в сумме $10,0 \mathrm{~cm}^{3}$ растворов кобальта $\left(\mathrm{CoSO}_{4} \cdot 7 \mathrm{H}_{2} \mathrm{O}\right.$, ч. д. а.) и нитрозосоединения, взятых в разных соотношениях. Концентрация обоих растворов была $2 \cdot 10^{-4}$ моль/дм ${ }^{3}$. В случае избытка окрашенного аниона нитрозосоединения долю комплекса в суммарной оптической плотности, измеренной при 415 нм, рассчитывали, полагая, что в этих условиях кобальт практически полностью связывается в комплекс. Результаты измерений показали, что в слабокислой среде ( $\mathrm{pH} 5,3)$ максимальная оптическая плотность, обусловленная комплексом, в случае обоих нитрозосоединений наблюдается при соотношении реагента и кобальта, равном $3: 1$, т. е. происходит окисление комплекса Сo(II) до $\mathrm{Co}(\mathrm{III})\left(\mathrm{CoA}_{3}\right)$. Напротив, в нейтральной и щелочной средах (рН 7,6 и 8,9) максимальной оптической плотности комплекса соответствует соотношение реагента и кобальта $2: 1 \quad\left(\mathrm{CoA}_{2}\right)$.

С точки зрения селективного связывания кобальта интерес представляет среда, в которой гидролиз посторонних катионов подавляется. Поэтому все дальнейшие исследования относятся к комплексу состава $\mathrm{CoA}_{3}$.

Определение констант устойчивости комплексов. Учитывая полное окисление Сo(II) до Сo(III) при комплексообразовании, общую константу устойчивости комплекса $\mathrm{CoA}_{3}\left(\beta_{3}\right)$ можно выразить как

$$
\beta_{3}=\frac{\left[\mathrm{CoA}_{3}\right]}{\left[\mathrm{Co}^{2+}\right]\left[\mathrm{A}^{-}\right]^{3}} .
$$

В настоящей работе константу $\beta_{3}$ определяли при $\mathrm{pH} 5-6$, т.е. в условиях практически полной диссоциации оксинитрозосоединения (AН). Равновесную концентрацию комплекса $\mathrm{CoA}_{3}$ измеряли спектрофотометрически.

Так как полосы поглощения $\mathrm{CoA}_{3}$ и $\mathrm{A}$ - перекрывают друг друга, для определения молярных коэффициентов поглощения этих форм (всо, и $\boldsymbol{\varepsilon}_{\mathrm{A}^{-}}$) проводили специальные опыты. Измеряли оптические плотности растворов в диапазоне спектра $450-550$ нм при исходных концентрациях кобальта $\left[\mathrm{Co}^{2+}\right]_{0}=0,2 \cdot 10^{-4}$ моль/дм ${ }^{3}$ и комплексообразователя $[\mathrm{AH}]_{0}=(1-4) \cdot 10^{-4}$ моль/дм ${ }^{3}$, а также в диапазоне спектра $550-600$ нм при $\left[\mathrm{Co}^{2+}\right]_{0}=0,5 \cdot 10^{-4}$ моль $/ д м^{3}$ и $[\mathrm{AH}]_{0}=(2,5-5,0) \cdot 10^{-4}$ моль $/$ дм $^{3}$. Все измерения проводили через сутки после приготовления растворов.

Измеряемая на любой длине волны $\lambda$ оптическая плотность $D_{\lambda}$ состоит из вкладов, обусловленных $\mathrm{A}^{-}$и $\mathrm{CoA}_{3}$ :

$$
D_{\lambda}=\varepsilon_{\mathrm{A}^{-}, \lambda}\left[\mathrm{A}^{-}\right] l+\varepsilon_{\mathrm{CoA}_{3}, \lambda}\left[\mathrm{CoA}_{3}\right] l,
$$

где $\varepsilon$ - молярный коэффициент поглощения на длине волны $\lambda, l-$ длина оптического пути (толщина кюветы). 
В условиях переизбытка комплексообразователя $\mathrm{AH}$ и его практически полной диссоциации $\left[\mathrm{CoA}_{3}\right]$ в равновесном растворе приближается к $\left[\mathrm{Co}^{2+}\right]_{0}$, а концентрация ионизированной формы комплексообразователя $\left[\mathrm{A}^{-}\right]$равна

$$
\left[\mathrm{A}^{-}\right]=[\mathrm{AH}]_{0}-3\left[\mathrm{Co}^{2+}\right]_{0} .
$$

Тогда уравнение (2) может быть записано в виде

$$
\frac{D_{\lambda}}{\left[\mathrm{Co}^{2+}\right]_{0} l}=\varepsilon_{\mathrm{CoA}_{3}, \lambda}+\varepsilon_{\mathrm{A}^{-}, \lambda} \frac{[\mathrm{AH}]_{0}-3\left[\mathrm{Co}^{2+}\right]_{0}}{\left[\mathrm{Co}^{2+}\right]_{0}},
$$

откуда легко определить $\varepsilon_{\mathrm{CoA}_{3}, \lambda}$ и $\varepsilon_{\mathrm{A}^{-}, \lambda}$ как коэффициенты линейной функции, описывающей зависимость $\frac{D_{\lambda}}{\left[\mathrm{Co}^{2+}\right]_{0} l}$ от $\frac{[\mathrm{AH}]_{0}-3\left[\mathrm{Co}^{2+}\right]_{0}}{\left[\mathrm{Co}^{2+}\right]_{0}}$.

Судя по результатам измерений (таблица), величины $\varepsilon_{\text {CoAs }}$ у комплексов нитрозоалкилрезорцинов того же порядка, что и $\varepsilon$ комплекса нитрозо-R-соли (согласно $\left[{ }^{13}\right]$, $\varepsilon$ этого комплекса в интервале спектра $490-610$ нм снижается от 17130 до 857 дм³ $/$ см · моль).

\section{Молярные коэффициенты поглощения нитрозоалкилрезорцинов}

\begin{tabular}{|c|c|c|c|c|}
\hline \multirow{2}{*}{$\begin{array}{l}\lambda, \\
\mathrm{HM}\end{array}$} & \multicolumn{2}{|c|}{ MRes-NO } & \multicolumn{2}{|c|}{ DMRes-NO } \\
\hline & $\varepsilon_{A^{-}} \cdot 10^{-3}$ & $\varepsilon_{\mathrm{COA}_{3}} \cdot 10^{-3}$ & $\varepsilon_{A^{-}} \cdot 10^{-3}$ & $\varepsilon_{\mathrm{CoA}_{3}} \cdot 10^{-3}$ \\
\hline $\begin{array}{l}450 \\
475 \\
500 \\
525 \\
550 \\
600\end{array}$ & $\begin{array}{l}1,75 \\
1,30 \\
0,56 \\
0,22 \\
0,08 \\
0,02\end{array}$ & $\begin{array}{c}22,6 \\
13,5 \\
8,20 \\
4,65 \\
2,68 \\
0,56\end{array}$ & $\begin{array}{l}2,07 \\
1,53 \\
1,13 \\
0,70 \\
0,27 \\
0,03\end{array}$ & $\begin{array}{c}19,8 \\
14,5 \\
10,8 \\
7,5 \\
5,9 \\
2,56\end{array}$ \\
\hline
\end{tabular}
$\left(\varepsilon_{\mathrm{A}^{-}}\right)$и их комплексов с кобальтом ( $\left.\varepsilon_{\mathrm{CoA}_{3}}\right)$, дм ${ }^{3} / \mathbf{c m} \cdot$ моль

Константы устойчивости комплексов кобальта с MRes-NO и DMResNO определяли в растворах с $\mathrm{pH} \mathrm{5,8} \mathrm{(ацетатный} \mathrm{буферный} \mathrm{раствор,}$ ионная сила 0,005$)$ при концентрациях нитрозосоединения $3 \cdot 10^{-4}$ моль/ дм ${ }^{3}$ и кобальта $1 \cdot 10^{-4}$ моль/дм ${ }^{3}$. В этом случае в равновесном растворе $\left[\mathrm{A}^{-}\right]=3\left[\mathrm{Co}^{2+}\right]$, и выражение (1) упрощается:

$$
\beta_{3}=\frac{\left[\mathrm{CoA}_{3}\right]}{27\left[\mathrm{Co}^{2+}\right]^{4}}=\frac{\left[\mathrm{CoA}_{3}\right]}{27\left(\left[\mathrm{Co}^{2+}\right]_{0}-\left[\mathrm{CoA}_{3}\right]\right)^{4}} .
$$

Так как в изучаемых условия х реакции $\left[\mathrm{A}^{-}\right]=[\mathrm{AH}]_{0}-3\left[\mathrm{CoA}_{3}\right]$, из уравнения (2) легко получить выражение для [CoA $\left.\mathrm{C}_{3}\right]$ :

$$
\left[\mathrm{CoA}_{3}\right]=\frac{D_{\lambda} / l-\varepsilon_{\mathrm{A}^{-}, \lambda}[\mathrm{AH}]_{0}}{\varepsilon_{\mathrm{COA}_{3}, \lambda}-3 \varepsilon_{\mathrm{A}^{-}, \lambda}} .
$$

Измерения на пяти образцах показали, что для MRes-NO $D_{500}$ составляет $0,690 \pm 0,009,\left[\mathrm{CoA}_{3}\right]-(0,799 \pm 0,015) \cdot 10^{-4}$ моль/дм ${ }^{3}$ и $\beta_{3}-(18,1 \pm$ $\pm 7,1) \cdot 10^{12}$ дм $^{9} /$ моль $^{3}$, а для DMRes-NO $D_{500}$ равняется $0,867 \pm 0,010$, $\left[\mathrm{CoA}_{3}\right]-(0,712 \pm 0,014) \cdot 10^{-4}$ моль/дм ${ }^{3}$ и $\beta_{3}-(3,83 \pm 0,95) \cdot 10^{12}$ дм $^{9} /$ моль $^{3}$. Из этих данных следует, что при $\left[\mathrm{Co}^{2+}\right]_{0}=1 \cdot 10^{-4}$ моль/дм ${ }^{3}$ и в условиях стехиометрического соотношения компонентов только $70-80 \%$ кобальта связано в комплекс с нитрозоалкилрезорцинами.

Для $95 \%$-ного связывания кобальта с концентрацией $1 \cdot 10^{-4}$ моль/дм ${ }^{3}$ исходная концентрация MRes-NO должна быть порядка $(3,8-3,9)$. 
$\cdot 10^{-4}$ моль/дм ${ }^{3}$, концентрация DMRes-NO - $(4,5-4,6) \cdot 10^{-4}$ моль/дм ${ }^{3}$, а для $99 \%$-ного связывания, соответственно, $(4,7-5) \cdot 10^{-4}$ и $(5,9-6)$. $\cdot 10^{-4}$ моль/дм ${ }^{3}$.

\section{Выводы}

1. Синтезированы новые реагенты для кобальта - 4-нитрозо-5-метилрезорцин и 4-нитрозо-2,5-диметилрезорцин.

2. Показано, что синтезированные нитрозоалкилрезорцины в слабокислой среде образуют с кобальтом комплексное соединение состава $\mathrm{CoA}_{3}$, в нейтральной и щелочной средах $-\mathrm{CoA}_{2}$.

3. Определены константы кислотной диссоциации нитрозоалкилрезорцинов в воде, молярные коэффициенты поглощения их анионных форм и комплексов с кобальтом $\mathrm{CoA}_{3}$ в области спектра 450-600 нм, а также константы устойчивости полной диссоциации комплекса $\mathrm{CoA}_{3}$.

\section{Л И Т Е Р А Т Р А}

1. Стары И. Экстракция хелатов. М., 1966.

2. Мельчакова Н. В., Пешкова В. И. Ассортимент реактивов на кобальт. М., 1970.

3. Перельман Ф. М., Зворыкин А. Я. Кобальт и никель. М., 1975.

4. Ягодин Г. А., Кузьмин В. И., Федотов О. Н. и др. Способ извлечения кобальта из водных растворов. - Открытия, изобретения, 1982, № 32, авт. свид. СССР № 954471 .

5. Поконова Ю. В., Проскуряков В. А., Левандовский В. И. Химия и технология сланцевых фенолов. Изд. ЛГУ, 1979.

6. Лилле Ю. Э., Кундель Х. А., Бродский Е. С. Новые данные о составе сланцевых фенолов. - Тр. Таллин. политехн. ин-та, сер. А, 1973, № 332, 199-208.

7. Тийкма Л. В., Мельдер Л. И. Распределение алкилрезорцинов при экстракции их смешанным экстрагентом. - Ж. прикл. хим., 1985, 58, № 7, 1564-1568.

8. Вейганд-Хильгетаг. Методы эксперимента в органической химин. М., 1969.

9. Кульберг Л. Н. Синтез органических реагентов. М.-Л., 1947.

10. Beilsteins Handbuch der organischen Chemie, 8. Berlin-Heidelberg, 1970, 2142.

11. Толмачев $B . H . \mathrm{K}$ вопросу о взаимосвязи между спектрами поглощения комплексных соединений и их прочностью. - Уч. зап. Харьковск. ун-та, 1957, 95. Тр. хим. фак. НИИ химии Харьковск. ун-та, 18, 153-166.

12. Краткая химическая энциклопедия, 3. М., 1964, 523.

13. Пятницкий И. В. Аналитическая химня кобальта. М., 1965.

14. Альберт А., Сержент E. Константы ионизации кислот и оснований. М., 1964.

15. Лурье Ю. Ю. Справочник по аналитической химин. М., 1971.

16. Комарь Н. П., Толмачев В. Н., Сизоненко Н. Т. Исследование окрашенных комплексов кобальта, нмеющих аналитическое значение. VII. Комплексное соединение с 1-нитрозо-2-нафтолом в цитратно-аммиачном растворе. - Уч. зап. Харьковск. ун-та, 1954, 54. Тр. хим. фак. НИИ химии Харьковск. ун-та, 12, 156161.

17. Kolthoff, I. M., Jacobsen, E. J. The composition and formation of cobalt complexes with 1-nitroso-2-naphthol. - J. Amer. Chem. Soc., 1957, 79, N 14, 3677-3681.

18. Комарь Н. П. Спектрофотометрия многокомпонентных смесей. II. Определение состава окрашенных соединений. - Уч. зап. Харьковск. ун-та, 1951, 37. Тр. хим. фак. НИИ химин Харьковск. ун-та, 8, 37-41.

$\begin{array}{cc}\text { Институт химии } & \text { Поступнла в редакцию } \\ \text { Академии наук Эстонской ССР } & \text { 3/XII } 1987\end{array}$




\section{NITROSORESORTSIINIDE SUNTEES JA KOMPLEKSIMOODUSTAMINE KOOBALTIGA}

On käsitletud 4-nitroso-5-metüülresortsiini ja 4-nitroso-2,5-dimetüülresortsiini sünteesi Eesti põlevkivi töötlemisel tekkivatest alküülresortsiinidest. On määratud saadud produktide happelise dissotsiatsiooni konstandid ja anioonse vormi molaarsed neeldumistegurid spektri piirkonnas 450-600 nm ning näidatud, et nitrosoresortsiinid moodustavad koobaltiga neutraalses ja ammoniakaalses keskkonnas kompleksühendi $\mathrm{CoA}_{2}$, nõrgalt happelises keskkonnas aga ühendi $\mathrm{CoA}_{3}$. On määratud komplekside püsivuskonstandid täielikul dissotsiatsioonil ja molaarsed neeldumistegurid spektri piirkonnas $450-600 \mathrm{~nm}$.

\section{Ille JOHANNES, L. MOLDER}

\section{NITROSORESORCINOLS AND THEIR COBALT COMPLEXES}

Synthesis of 4-nitroso-5-methylresorcinol and 4-nitroso-2,5-dimethylresorcinol from alkylresorcinols produced by oil shale thermal treatment is described. The constants of acid dissociation, coefficients of molar absorption of light by $450-600 \mathrm{~nm}$ and stability constants of the prepared nitrosoresorcinols and their cobalt complexes have been determined. 